\title{
IJCCE: A Communication Platform for Cleaner Production and Sustainability
}

\author{
Jianjun Zhang \\ School of Land and Technology, China University of Geosciences, Beijing, China \\ Email: zhangjianjun_bj@126.com, zhangjianjun@cugb.edu.cn
}

Received August 25, 2013; revised September 26, 2013; accepted October 4, 2013

Copyright (C) 2013 Jianjun Zhang. This is an open access article distributed under the Creative Commons Attribution License, which permits unrestricted use, distribution, and reproduction in any medium, provided the original work is properly cited.

\section{Introduction}

It is clear that global climate change and global warming has been the world-wide focus of concern as well as one of the most serious problems human beings have to face. The terrible situations seem to shock the scientists' brains for a long time. Both in developed and developing countries, scientists and engineers attempt to seek for solutions to mitigate and even control environmental degradation. So, the improvement of technology and management is extremely essential in the current stage. Clean coal and energy seems an old topic but actually a new one because the related issues have greatly impacted people's daily life and the solutions need intervening by governments. It has become not only an academic topic but also a social one. By writing this communication, I want to spend a little time unraveling the thoughtful framework of running IJCCE by posing and answering four questions as below. In fact, these questions regulate the order of knowing IJCCE for authors and readers.

- Whom does IJCCE serve for?

- Why can IJCCE attract people's attention?

- What can IJCCE bring to the world?

- How can IJCCE transmit new/good information to the world?

\section{Question I: Whom Does IJCCE Serve for?}

When you see this question, there may be an "interrogation mark" or an "exclamatory mark" into your brain. Yes, there is a simple question, but why is it posed? Here, I want to emphasize that the people IJCCE serves for are not only fixed on scientists or engineers. How to keep healthy environment and how to further keep economic sustainability within environmental improvements? To reach the trade-offs between economy and environment, we need more concerns from enterprises and governments. That is to say, IJCCE serves for two kinds of peo- ple, policy-making supporters and policy makers, composed of researchers, officers or even related civilians. These people become whom IJCCE serves for as long as they are involved in the activities related to clear coal and energy. IJCCE is to establish such a communication platform for article contributors, readers, information transmitters and research communicators etc. across the world, through which they can obtain the information about related theory, technology and study cases they need and also transmit the ideas, methods, practices and experience to the world.

\section{Question II: Why Can IJCCE Attract People's Attention?}

There are also some journals concerning about clean coal and energy, but each journal has its characteristics. As a new journal in the field of clean coal and energy, IJCCE keeps its own characteristics and still attract people's attention as it grasps the new directions in which it is likely to process in future. Besides, the information IJCCE transmits to the world implies two key points: cleaner production and sustainability, covering the related issues of coal and energy in theory, technology and practice. To respond to this question, let's focus on the objects of IJCCE.

Currently, the study on clean coal and energy is not only confined to the quality of products and production process, and the research objects have been extended to a series of issues caused by the extraction of coal and energy. In general, the objects are categorized by their relationships with coal and energy into five types: new and renewable energy, upgrading technologies, economical and governmental issues, safety and security issues and environmental impacts.

- The first type of objects covers new findings in extraction process or technological upgrading of newly developed renewable energy, including solar energy, wind energy, geothermal energy, hydro energy etc. 
Most people have been very familiar with some or even all of them, but how to raise efficiency is still a serious problem. With the development of science and technology, more and more alternative energy and resources, such as biomass energy, will be developed and applied in daily production and living, which will greatly change human living styles one day.

- For the second type of objects, it is emphasized more on advanced technology in energy processing, including refined coal, nanotechnology and biotechnology, production of coal liquid, storage and transportation, future technology etc. When we cannot avoid consuming non-renewable energy and resources and yet have to face energy-induced environmental issues, the upgrading of technology becomes an important way but also the only way to mitigate environmental deterioration. The technological updating, macro or micro, in any step of energy exploration, production, processing, storage or transportation has a significant influence on improving the capacity of cleaner production.

- The third type of objects is focused on economical and governmental issues related to coal industries, including coal business, international trade regulations, governmental policy etc. Social development and prosperity cannot live without economic contributions. Financial and political support is the essential basis of technological upgrading. Besides, economical and governmental involvement can promote the widespread applications in industrial production and governmental policy making. Here, IJCCE wants to deepen the understanding of cleaner production and sustainability, not only within environmental considerations but taking economical understanding into account, aiming at minimizing waste and emissions and maximizing product output.

- About safety and security issues, the objects refer to any aspect in technology, operation and management, which has a possible negative impact on people and production. These issues, bundled with coal and energy processing, are the precondition of regular production. And they themselves are one of the key considerations in cleaner production and sustainability.

- The fifth type of objects is closely related to environments composed of land, water, vegetation, soil, air, dust and even noise, possibly impacted by the extraction of coal and energy. According to the research frontier and tendency in this field, I want to address the essential extending of clean coal and energy to environments, not only carbon emissions, but more related issues need considering, such as mined land reclamation, mine water treatment, contaminated soil remediation etc. Actually, solving extraction-induced issues has played an important role in cleaner production and sustainability.

Thus, IJCCE covers a series of contents about clean coal and sustainability, from theory to practice, from technology to management and from research to application. Authors and readers can find their own space and also share their ideas, methods and experience. On that, IJCCE, as a free talking forum, provides a variety of article types and welcomes opinions, discussion, debate and even possible cooperation, a symbol of academic diversity. IJCCE encourages the publication of quantitative and qualitative studies rich in advanced technology, methodology and experience, especially in innovative study cases, which are published as new ideas, research processes and results, technological innovation, case studies etc. IJCCE is also concerned about the development of this field in clean coal and energy, so the article reviews and book reviews are taken into account for publication. What is more, this journal will track the dynamic news and intend to discuss cleaner production and sustainability as a professional field, and therefore conference reports and industrial reports are accepted by IJCCE. Besides, this journal will call for papers published in a special issue according to authors' and readers' requirements and hot topics. What I would like to emphasize that coal and energy in developing countries will be given more attention as these countries need address their difficulties and more aspire to introduce advanced technology and experience. As an open and free professional field and a public space, in which ideas and practices can be tested and accepted, IJCCE will give authors and readers more opportunities and ways for the expression of common academic concerns.

\section{Question III: What Can IJCCE Bring to the World?}

Extending from the extraction steps (exploration, production, processing, storage and transportation) of coal and energy to project management and policy making (economical, managerial, business, environmental, safety and security issues), IJCCE, as a dissemination tool, aims at transmitting advanced knowledge and experience related to coal and energy for cleaner production and sustainability. For the surviving of a journal, the quality is its concrete foundation but what the journal can bring to the world also determines how far it can go forward. Why IJCCE attract people's attention tells us what it can bring to the world. I adopt five phrases starting with $\mathrm{C}$, entitled " $5 \mathrm{C}$ "s, to respond to this question. What IJCCE can bring to the world is, actually, all kinds of information. Let's see the category as follows:

- Conceptual Idea

As an academic journal, the contributors of IJCCE are composed of researchers, scholars, engineers and teach- 
ers etc. Their research frameworks and conceptual ideas from a program are presented in the publications. Perhaps these ideas are only the ones in brains, but they may still be the foundation for other relevant programs.

- Clean Technology

Besides conceptual idea, IJCCE will introduce advanced clean technology to the world. The success of cleaner production starts from the upgrading of technologies, even from the improvement of a technical parameter. The successful technology published in IJCCE can be tested and shared across the world.

- Commercial Opportunity

Though clean coal and energy is aimed at environmental improvement, the research and applications, as mentioned above, cannot survive without economic support and driving. On the face of it, IJCCE provides a communication platform for addressing ideas and technologies, but commercial hunters can gasp economic information. In fact, it is a virtuous circle of "proposing ideas and technologies $\rightarrow$ operating commercial business $\rightarrow$ upgrading ideas and technologies".

- Constructive Experience

Constructive experience is mainly fixed on energy extraction and industrial management. Ideas and technologies are very important, but successful experience can effectively save manpower, resources and money. This piece of information needs bundling with advanced ideas and technologies together for the maximum of cleaner production and sustainability.

\section{- Cooperation}

The authors and readers of IJCCE, professional in one aspect of the field, come from all over the world. But one program needs a number of experts to reach the achievements, so this journal builds a bridge for linking them together. Additionally, developing countries also need the technological helps and support from developed countries. IJCCE wants to transmit relevant information to world for assisting people, enterprises, research institutions and governments in seeking for their cooperative partners.

\section{Question IV: How Can IJCCE Transmit New/Good Information to the World?}

According to various requirements and different cultural backgrounds of authors and readers, we accept a variety of types of contributions, including research paper, review paper, report, communication, viewpoint, profile etc. Our service initiative is to transmit authors' ideas and practices to the world. However, the authors are subject to a rigorous and fair peer-review process like other journals. First-round, second-round and even thirdround reviews are essential during the process. Once one article is accepted, it will be available online soon through Open-Access publishing in Scientific Research Publishing. Different from traditional publishing, OpenAccess publishing makes authors' work immediately and permanently available online for everyone, worldwide, and the readers can easily and freely download authors' articles to get what they want to transmit at the first time. What is more, a distinguished group of scholars and engineers with experience and expertise in the field of clean coal and energy, from Australia, China, Poland, Spain, the United Kingdom and the United States, have accepted invitations to join the editorial board, to support the development of IJCCE and this field. We will also transmit new/good information published in IJCCE to the world by our influence and ways.

Having responded to the four questions, I believe that you have known more about this new journal. IJCCE is to provide an even greater focus on the articles which are closely related to clean coal and energy and to develop this field in such a way as ensure that this journal reflects leading findings and developments in cleaner production and sustainability across the world. What we have been doing for IJCCE will amount to little without the support of authors and readers, and your active participation will be significant and crucial to create a truly academic platform in cleaner production and sustainability. I am sure that IJCCE will devote itself to the healthy, peaceful and sustainable development of human society in the future. 